\title{
Preservice Teachers' Perception and Use of Personal Learning Environments (PLEs)
}

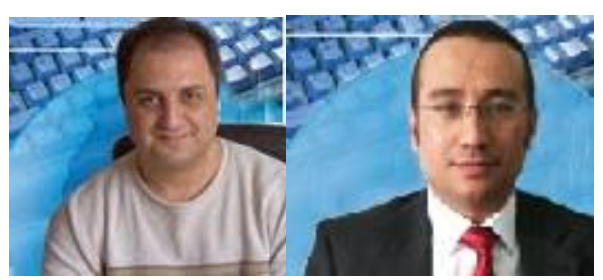

Sami Şahin and Çelebi Uluyol

Gazi University, Department of Computer Education and Instructional Technologies, Turkey

\begin{abstract}
Personal learning environments (PLEs) are Web 2.0 tools and services by which users' access, construct, manage, and share educational contents in order to meet their learning needs. These environments enable users to manage their learning according to their own personal preferences. They further promote socialization and collaboration with their broad user networks and interaction facilities. In this study, with a case sample from a public university in Turkey, student teachers' PLE use and their perceptions regarding these environments are examined. For data collection, the PLE Perception Scale and PLE Use Scale developed by the researchers were used. It was observed that all participants used various PLEs and found them easy and practical on the whole. However, it was found that this utilization mostly had the aim of access and sharing knowledge in learning, while use of constructing and managing it remained limited. Emailing, social networking, file sharing, video sharing, Internet searching, and social encyclopedias were found most commonly used PLEs. Our findings also show that gender and grade level do not have an effect on the perception and use of PLEs.
\end{abstract}

Keywords: personal learning environments, perception, use, preservice teachers 


\section{Introduction}

Over the past decade Internet users have become able to meet their various learning needs and communicate with their peers, teachers, and communities of interest for educational purposes by using Web 2.0 tools and services. This situation has resulted in the concept of personal learning environments (PLEs) in the field of learning technologies (Buchem, Attwell, \& Torres, 2011; GodwinJones, 2009; Attwell, 2007; O'Reilly, 2006; Johnson, Hollins, Wilson, \& Liber, 2006; Chan, Corlett, Sharples, Ting, \& Westmancott, 2005; Mitsuhara \& Kurose, 1999).

Personal learning environments (PLEs) are Web 2.0 tools and services by which users access, construct, manage, and share knowledge and educational contents in order to meet their learning needs (Johnson \& Sherlock, 2014; Fiedler \& Väljataga, 2013, 2011, 2010; Buchem, 2012; Jeremic, Jovanovic, \& Gasevic, 2011; Oliveira \& Moreira, 2010). These environments not only enable users to control and manage their learning but also contribute to their socialization. Students can share their lecture notes, course resources, and homework with their classmates and carry out collaborative learning activities by cooperating in these environments. Teachers can also share lecture notes and contents with their colleagues accordingly.

According to Attwell (2007), PLEs are activity environments whose final outcome is cooperative learning, where learners communicate and interact with other learners and experts. These environments assign learners an active role by putting them at the center of the learning process and increase learners' control of their own learning at the same time (Downes, 2006; Buchem, 2012). In these environments learners do not only access learning content but also form content themselves and share that content by submitting it to other learners (McLoughlin \& Lee, 2010). Thus, with this assistance, they can manage their own learning and work towards their educational goals (Educase Learning Initiative, 2009).

PLEs have been attracting the interest of researchers since 2008 (Johnson \& Liber, 2008; Liber \& Johnson, 2008; Powell, Tindal, \& Millwood, 2008; Severance, Hardin \& Whyte, 2008; Wilson, 2008; Chatti, Jarke, \& Specht, 2010; Drexler, 2010; Mödritscher, 2010; White \& Davis, 2011; Dabbagh \& Kitsantas, 2012; Valtonen et al., 2012; Conde, García-Peñalvo, Alier, \& Piguillem, 2013; Juarros, Ibanez, \& Crosetti, 2014; Shaikh \& Khoja, 2014). According to Fournier, Kop, \& Durand (2014), PLEs are still in their infancy and hence a description of the current situation is a necessary starting point for all studies related to PLEs. This research therefore aims to examine the current real-world usage of PLEs by developing scales to evaluate preservice teachers' usage and perceptions of PLEs and to provide an analysis of those findings accordingly. PLEs hold ever-increasing potential in meeting the personal, social, and professional learning needs of all Internet users in general and preservice teachers in particular (Valjataga \& Laanpere, 2010; Cseh \& Manikoth, 2011).

\section{Types of PLEs}


Various PLEs are mentioned in the literature (Saadatmand \& Kumpulainen, 2012; Wilson, 2008). They can be categorized into certain categories, with examples as follows.

Homepages. These environments enable their users to simultaneously access more than one Web 2.o tool on the same page and manage their content. Thus, time is saved by simplifying the users' work. Users can manage their learning processes by reviewing the updates generated from Web 2.0 environments on their homepages at a single glance. Google+ is an example of one such commonly used homepage.

Encyclopedias. These environments allow users to create shared encyclopedias in the fields of current issues, general education, or other personal interests. These environments further enable users to participate as both author and referee, with opportunities to benefit from personal reading while also benefitting the broader public audience by their own publications. Such online environments are steadily replacing printed encyclopedias. The best such example is Wikipedia, a key example of a successful online encyclopedia purely driven by user-submitted content.

Search engines. With search engines, learners are able to access the needed information and content with various filtering options (keywords, year, language, author, video, visuals, graphics, etc.) from different sources. Search engines have become an irreplaceable part of the modern-day learning process. In light of the fact that the Internet has turned the whole world into a virtual library, search engines have logically become this library's catalog; in other words, they have replaced the classical library catalogs. Google, Yandex, and Yahoo can be cited as some commonly used search engines.

Networks. Networks are virtual meeting zones where people can interact with their families, friends, acquaintances, and colleagues while surfing the Internet. Such social environments can also form a sub-framework within other Web 2.0 tools. For example, users can share YouTube videos on Facebook. In a sense, such environments function as a metaphorical school playground; users can check in at random as time allows, particularly in between classes in the case of students, giving them a symbolic "recess". Facebook is one of the most commonly used social network.

Documents. Online file sharing tools are cooperative environments in which users can share their files and conduct collaborative projects by exchanging files synchronously or asynchronously, even if they do not use the same basic online environments. Learning content is formed, saved, and shared via these shared documents. This allows the constant continuation of the learning process everywhere via mobile devices, and, in this sense, document sharing is one of the most valuable applications among the multiple possible uses of PLEs. Google Docs is the forerunner of such file sharing possibilities.

Email. Electronic messages have taken over the role of classical letters. This functionality was one of the very first tools that the Internet provided to its users and it has become undeniably widespread. Not only does email offer binary correspondence environments, but it also offers safe platforms for the private sharing of electronic content via the add function. In such environments, people can also share chosen information by creating groups, and email enables users to easily find their incoming and outgoing messages when needed by archiving them. Gmail is a particularly commonly used example of email applications. 
Graphics. Users can also share graphics via PLEs. People can obtain visual items and edit and share them within these environments, not only for fun and socialization but also for educational purposes. Tools like Picasa and Instagram can be named as examples.

Blogs. Blogs are personal publication tools. Users can share their information, their findings, and all other varied interests with their followers, and they can further archive their shared information and reorganize such data whenever they want. It is easy to establish and publish blogs. Blogs are easily shared PLEs and thus replace classical personal websites with this usability. Blogger and WordPress are commonly used examples of blog environments.

Microblogs. Microblogs are distinct from blogs in terms of limited sharing with a restricted number of characters; for instance, Twitter posts are limited to 140 characters. Users typically share current featured news and their opinions or reactions concerning events. In recent years, microblogs have become highly effective socially, especially with their influence in policy-making. Twitter is the most commonly used microblog.

Chats. Chats are electronic environments that make written communication or both written and voice communication possible in order to provide real-time bilateral or multilateral interaction. Written, voice, and video chats have gradually become widespread as Internet technologies provide faster and broader network access. While video chats are preferred for more official uses like video conferences, written or text-based chats are less professionalized while remaining widely used. Chats also serve as online meeting rooms in cooperative learning. Skype can be cited as the most commonly used chat environment.

Presentations. Users both provide learning support to other users and receive feedback and reflections on their own work by sharing their learning materials with others in the form of presentations in PLEs. Thus, users can spread learning content and increase their own knowledge as well. SlideShare can be given as an example of these environments.

Calendars. Users can create personal or cooperative work calendars and track their activities from said calendars. As today's learner-centered, cooperative, active learning approaches give bigger roles and workloads to the learners themselves, the importance of Web 2.0 calendars is clear. Google Calendar is an example of these environments.

Videos. PLEs also allow users to share their videos. Today, mobile devices are in the hands of almost every learner. These devices can record, process, and save videos in high resolution with smart operating systems and large memories. Users can quickly access Web 2.0 environments and download, upload, and watch videos via these devices. Web 2.0 video environments can be easily installed on electronic devices while recorded videos can be shared instantly. YouTube is an example of these environments.

\section{Features of PLEs}


PLEs have distinctive characteristics that give them an advantage over classical learning environments (Hicks \& Sinkinson, 2015). These are summarized below.

Open access. Users can join these environments free of charge, download tools, and make individual choices. In light of the fact that commercial educational software, services, and tools can be very expensive, and especially with the updating and maintenance costs considered, open access shines as one of the most explicit virtues of PLEs.

Multithreading. Users can engage simultaneously in interaction and cooperation with a high level of participation in learning activities (Chatti, Dakova, Thüs, \& Schroeder, 2013; Marin, Negre, \& Perez, 2014). For example, Google Docs provides a convenient environment to create shared documents online.

Convenience and Usability. PLEs can be used by individuals of different age groups and varied personal characteristics because they are developed by targeting large masses and updated according to broad user feedback (Fournier \& Kop, 2012).

Individualization. One of the most significant features defining PLEs is that they are customizable (Saadatmand \& Kumpulainen, 2012). Users can control and manage these environments according to their own personal preferences (Valjataga \& Laanpere, 2010). This is an outstanding advantage considering the fact that user control is limited in classical learning management systems Milligan et al., 2006). This feature also contributes to learners' independent learning and selfregulation skills (Valjataga \& Laanpere, 2010).

Usefulness. A great deal of PLEs were developed at the same time, with the most convenient ones becoming widespread; this makes it possible to find environments devoted to almost any kind of learning need. Technology acceptance studies often prove that user-friendliness is a critical factor in the proliferation of new applications and tools (Park, 2009; Shroff, Deneen, \& Eugenia, 2011; Teo, 2009; Teo, 2010; Ursavaş, Şahin, \& Mcilroy, 2014).

Sociability. PLEs are not only learning environments but also good socialization environments with written and visual communication channels. Users are able to create common understanding and shared knowledge in these environments, acting together with simultaneous opportunity for self-reflection.

Prevalence. PLEs have broad user networks (Hicks \& Sinkinson, 2015). This prevalence provides plentiful resources and access options to users. With this feature, PLEs are applicable for creating large study groups; additionally, in these environments people can establish contacts with individuals from almost any community of interest. Facebook, Twitter, Wikipedia, and YouTube can be named as examples of online environments with particularly broad prevalence.

\section{Limitations of PLEs}


As is the case with all new technologies, there are inherent limitations to PLEs that need to be noted and studied (Fournier, Kop, \& Hanan, 2012). These are listed below accordingly.

Phishing. The virtual world poses risks to those users who cannot manage their update, privacy, and security settings, and therefore many Internet users worry that their identity information and digital entities could change hands (Shankar, Elliott, \& Fitchett, 2009). PLEs are no strict exception. The large user groups of PLEs and their open access features can be perceived as limitations that might create a risk of phishing (Salehi, Kamalabadi, \& Ghoushchi, 2013).

Advertisements. Because PLEs provide open access at no charge to their users, their organizers may be driven to collaborate with broadcasters and other commercial groups to accept donations or advertisements to cover the PLE's expenses. However, these advertisements, appearing as boxes on PLE interface screens, can distract users, making concentration difficult for them and resulting in negative attitudes toward the PLEs if the users feel disturbed or distracted by ads (Kazançoğlu, Üstündağlı \& Baybars, 2010).

Cyber bullying. The acceptance and normalization of novel technologies by users takes time and victimization can occur, particularly at the beginning, as incorrect and malicious usage of these tools occurs. Web 2.0 environments, with their usability and prevalence, and as places where identities can remain anonymous, have created an open environment for cyber bullying. Despite the fact that the novelty of Web 2.o has decreased with time, cyber bullying still exists as a limitation for these environments (Childnet International, 2013).

Q\&A cycles. In PLEs, questions and answers intended to inform or guide the user are displayed on the user's screen during startup or use. However, the repetition of the same Q\&As at subsequent log-ins and the emergence of new questions that are easily answered can be annoying for the user. Although this situation has gradually decreased by comparison with the first era of Web 2.0 tools, it is still acknowledged as a problem.

\section{Purpose of the Research}

According to Fournier, Kop, \& Durand (2014), PLEs are still in their infancy and hence a description of the current situation is a necessary starting point for all studies related to PLEs. The purpose of this research is to examine the PLE usage of preservice teachers and reveal their perceptions of these environments. In this context, the development of PLE perception and usage scales was among the objectives of this research. In accordance with these purposes, answers are sought for the following research questions:

What is the validity and reliability of the PLE Perception Scale? 
What is the distribution of the participants in terms of the PLE Perception Scale?

What is the distribution of the participants in terms of the PLE Use Scale?

Furthermore, attention is given here to an evaluation of how the research findings vary according to variables of gender and grade level is also examined.

\section{Materials and Methods}

The research was carried out by survey method in which researchers collect data to examine the distribution of a sample in respect to research variables (Cohen, Manion, \& Morrison, 2007). For the survey, a questionnaire developed by the researchers was used in order to evaluate the students' use of PLEs and their perceptions regarding these environments.

The sample population consisted of 109 students in total (66 females and 43 males) who were student teachers at a public university in Turkey, in the fall semester of the 2014-2015 academic year. Twenty-three of these students were second grade, 41 of them third grade, and 45 of them fourth grade. First grade students were not included in the analysis because of their low level of voluntary participation. All participants had regular access to the Internet in multiple environments: 70 students with home access, 69 with school access, 37 with dormitory access, and 76 with access to the Internet via mobile phones.

A thorough literature search was conducted to identify PLEs used commonly by students. The review included 112 research review articles in Web of Science journals published between the years 2008 and 2015, Google searches, reviews of expert opinion (three researchers in the field of instructional technology), and an open-ended survey (Web 2.0 tools which student teachers use). Consequently, 24 PLEs within 13 types (Table 3) fell within the relevant scale of review. In order to evaluate the students' perceptions of these 24 selected PLEs (Table 3), variables were determined on the basis of the following two main sources: the characteristics of the PLEs themselves and a review of variables denoted as significant in the published literature on the technology acceptance model (TAM; Teo, 2009; Teo, 2010, Ursavaş, Şahin, \& Mcilroy, 2014).

According to TAM, users' technology acceptance is mainly determined by two sources of perception which are perceived usefulness and perceived ease of use. Davis (1989) defined perceived usefulness as the degree to which a person believes that using a particular system would enhance his or her job performance and perceived ease of use as the degree to which a person believes that using a particular system would be free from effort. In this study we adapted perceived usefulness as the degree to which a learner believes that using PLEs would enhance his or her learning and perceived ease of use (usability) as the degree to which a learner believes that using PLEs would be free from effort. Another factor was perceived limitations (Fournier \& Kop, 2012; Notar, Padgett \& Roden, 2013).

Data collection was conducted online by Google Forms while an explanatory statement was posted to the students' social networking group to encourage participation. Additionally, the course instructors of relevant classes were requested to encourage participation and provide support for the follow-up. 
The measurement scale remained active online for two weeks, and a reminder was posted at the end of the first week.

The PLE Perception Scale employed here was a 5-point Likert-type scale (1: Strongly disagree, 2: Disagree, 3: Undecided, 4: Agree, 5: Strongly disagree). The numerical intervals that corresponded to each category in the scale were as follows: 1.00-1.80, Strongly disagree; 1.81-2.6o, Disagree; 2.61-3.40, Undecided; 3.41-4.20, Agree; and 4.21- 5.00, Strongly disagree. The survey questions were asking about PLEs in general not about a specific PLE. On the other hand, the PLE Use Scale was in the form of check boxes and users could select one or more route of access, construct, management, or share options for each specific type of PLEs.

\section{Results and Discussion}

Principal axis factoring (PAF) was carried out using SPSS 20 in order to discover the structure of the PLE perception scale. PAF is a factor analysis technique commonly used in the social sciences; it attempts to explore the least number of factors which could account for the common variance (correlation) of a set of variables. Before applying PAF, within the scope of evaluation of parametric test assumptions, the size of the sample was checked with the Kaiser-Meyer-Olkin test and was found to be sufficient $(\mathrm{KMO}=.734)$. The criterion for KMO sample sufficiency was determined as .60 (Tabachnick \& Fidell, 2013). Moreover, the equality of variance for the sample distribution was analyzed with the Bartlett test and was also found to be sufficient $\left(\chi^{2}=433.812, S D=55, p<.001\right)$. Promax rotation is preferred for PAF and is one of the most widespread techniques used in the social sciences, with the intention of maximizing the loading of each selected input factor and hence reducing the complexity of the factors (Tabachnick \& Fidell, 2013).

In determining the number of factors, an eigenvalue of $\geq 1$ was used as the cut-off for possible inclusion (Tabachnick \& Fidell, 2013). The cut-off point for the loading values was .45 while deciding which variable belonged to the factors (Tabachnick \& Fidell, 2013). According to Comrey and Lee (1992), a loading value of .71 or above is excellent, of .63 or above is very good, of .55 or above is good, of .45 or above is sufficient, and of .32 or above is low. The extraction of the variables that passed the loading cut-off point under multiple factors was also considered as a criterion (Stevens, 2009). In consideration of these standards, the extraction of three items from the scale was considered appropriate and thus the final shape was given to the analysis.

Looking at the PAF results (Table 1), items are grouped under three factors of usability, usefulness, and limitation. The usability factor explains $28.78 \%$ of the variability of the whole scale, while the usefulness factor explains $14.03 \%$ and the limitation factor explains $10.38 \%$. These three factors together explain $53.18 \%$ of the scale's variability. Other items with loading values under the cut-off limit of .45 were not included in the table.

Table 1

PLE Perception Scale Principal Axis Factoring Item Weights

\begin{tabular}{|c|c|c|c|}
\hline Items & Usability & Usefulness & Limitation \\
\hline Easy to use & .924 & & \\
\hline Easy to access & .778 & & \\
\hline Easy interaction with other users & .741 & & \\
\hline
\end{tabular}




\begin{tabular}{|c|c|c|c|}
\hline Allows for personal preferences and control & .770 & & \\
\hline I find it useful in my personal development & & .771 & \\
\hline I think it offers up-to-date content & & .677 & \\
\hline I find it useful in my student life & & 641 & \\
\hline I find it useful in my socialization & & .530 & \\
\hline Q\&A cycles are annoying & & & .793 \\
\hline I think I am exposed to phishing & & & .739 \\
\hline I am exposed to cyberbullying & & & .491 \\
\hline
\end{tabular}

After discovering the factors, a confirmatory factor analysis (CFA) model was also designed and tested by the SPSS Amos 22 program in order to evaluate the construct validity of the PLE perception scale (Figure 1). The results showed that there was sufficient fit with the model data $\left(\chi^{2}=1.414\right.$, GFI $=.916$, CFI = .961; RMSEA = .062; Byrne, 2009). According to the model, while there is a small (.37) but significant $(p<.01)$ correlation between usability and usefulness, there is no correlation between usability and limitation. On the other hand, there is small negative correlation (-.15) between limitation and usefulness, but this is not significant ( $p>.05)$. With each factor's items considered, the regression coefficients are in the range of $.48-.94$ and all appear to be significant $(p<.001)$. These results indicate that the validity of the scale, consisting of 11 items under three components, is acceptable.

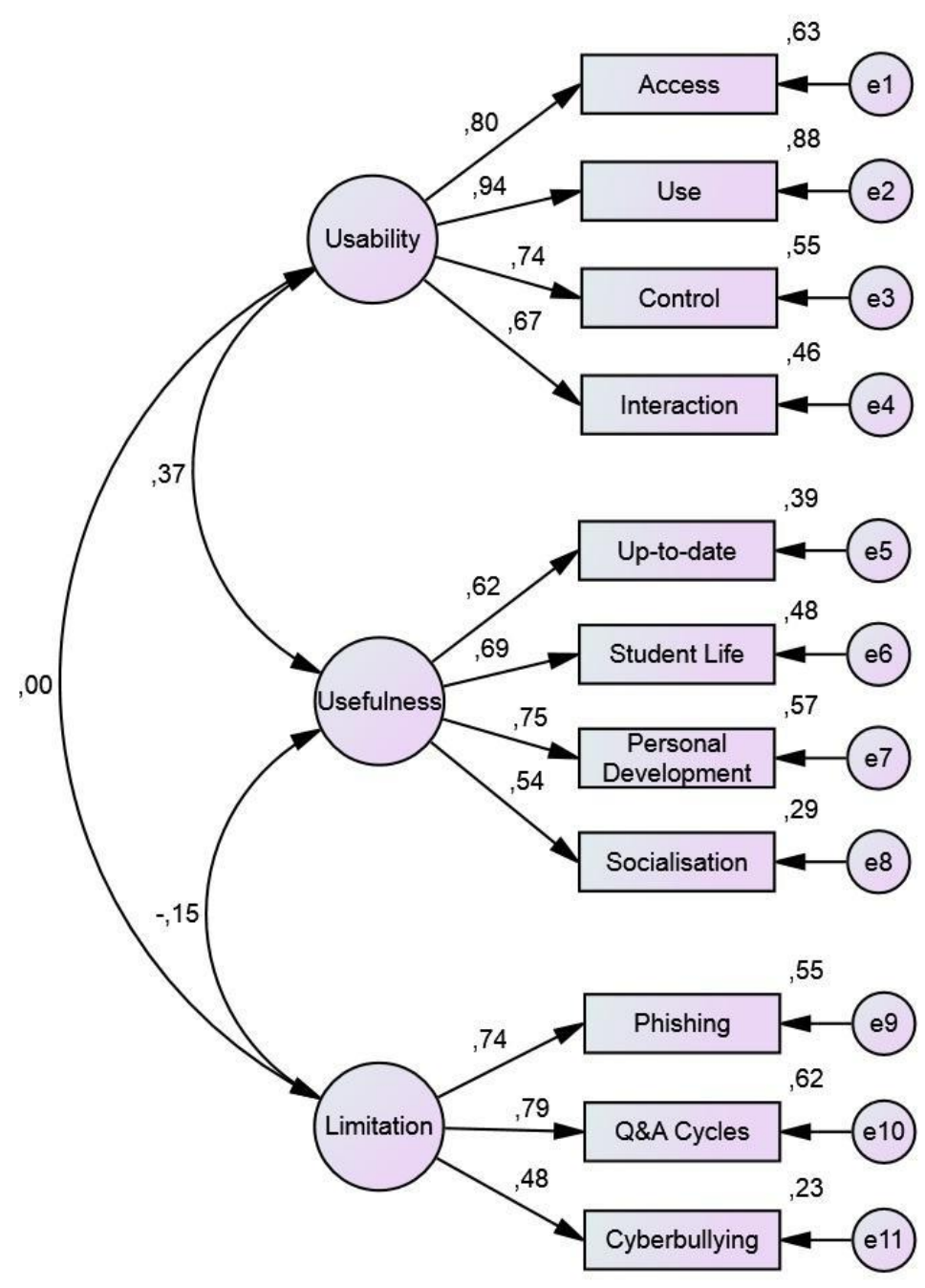


Figure 1. The PLE perception scale CFA results (e refers to each item in the scale)

To evaluate the reliability of the PLE Perception Scale, Cronbach's alpha was calculated for each factor. For usability .86, for usefulness .79, and for limitation .71 was found. Hinton (2004) stated that the reliability of a measurement would be considered acceptable for alpha coefficients above .70 .

Table 2 gives the means and standard deviations for the PLE Perception Scale. For usability, responses for each items are in the "strongly agree" level and the highest rate of such agreement belongs to "easy interaction with others". Looking at the items belonging to usefulness, responses are in the "strongly agree" level for "I find it useful in my student life" and "agree" for the others. In this component, the lowest support was expressed for "I think it offers up-to-date content". Items diverged in terms of agreement level when considering limitation. Although "Q\&A cycles are annoying" was answered with "agree", "I think I am exposed to phishing" received an "undecided" response while "I am exposed to cyberbullying" received "disagree". According to the standard deviations, students' agreement diverges more in the items of limitation. Students are more in accord with each other about the items of usability, as reflected by standard deviations. Consequently, we can say that students' usability perceptions regarding PLEs are very high, while their usefulness perception is high. In terms of limitation, they find Q\&A cycles annoying, they are not exposed to cyberbullying, and they are undecided as to whether or not they are exposed to phishing.

Table 2

The PLE Perception Scale Means and Standard Deviations

\begin{tabular}{lcc}
\hline Items & $\boldsymbol{M}$ & $\boldsymbol{S D}$ \\
\hline Easy to use & 4.31 & .54 \\
Easy to acces & 4.33 & .49 \\
Easy interaction with other users & 4.35 & .62 \\
Allows for personal preferences and control & 4.22 & .72 \\
I find it useful in my personal development & 3.98 & .86 \\
I think it offers up-to-date content & 3.64 & .69 \\
I find it useful in my student life & 4.23 & .60 \\
I find it useful in my socialization & 3.96 & .88 \\
Q\&A cycles are annoying & 3.57 & .01 \\
I think I am exposed to phishing & 3.20 & .10 \\
I am exposed to cyberbullying & 2.47 & .03 \\
\hline
\end{tabular}

Note. $M=$ sample mean; $S D=$ standard deviation. 
Table 3 summarizes the PLEs used by the students according to type, name, and role in the learning process. The PLEs most commonly used by students by type are emails, networks, documents, videos, search engines, encyclopedias, blogs, microblogs, graphics tools, video talk, messengers, presentation platforms, homepages, and calendars, in that order. The environments not included in the PLE Use Scale that students wanted to add were also Web 2.0 notes $(n=1)$, forms $(n=4)$, forums $(n=6)$, and dictionaries $(n=8)$.

Table 3

The Frequency Distribution of the Users According to the PLE Use Scale $(N=109)$

Type of PLEs

1. Email

2. Network

3. Document

4. Video

5. Search Engine

6. Encyclopedia

7. Network

8. Document

9. Blog

10. Mikroblog

11. Photography

12. Chat

13. Chat

14. Video

15. Blog

16. Video

17. Document

18. Presentation

19. Chat

20. Network

21. Video

22. Graphic

23. Homepage

24. Calendar
Tool/Service Frequency Distribution Access Construct Manage Share Mean

Gmail $\quad 54$

Facebook

Google Drive

59

YouTube

Google Search

Wikipedia

Google +

Dropbox

Blogger

Twitter

İnstagram

Skype

MSN Messenger

Expert TV

WordPress

Dailymotion

Google Docs

Slide share

Google Talk

45

45

99

51

44

58

58

36

98

102

45

41

50

42

45

33

33

25

35

23

23

24

19

15

16

82

44

43

Myspace

Vimeo

Flicker

iGoogle

Google Calendar

Mean
66

26

\section{0}

14

13

32

9

14

10

40

26

10

43

43

$\begin{array}{lll}88 & 81 & 69\end{array}$

$\begin{array}{lll}54 & \mathbf{9 7} & 64 \\ \mathbf{8 5} & 48 & 59\end{array}$

$85 \quad 48 \quad 59$

$\begin{array}{lll}36 & 62 & 58\end{array}$

$\begin{array}{lll}38 & 37 & 54\end{array}$

$\begin{array}{lll}30 & 31 & 52\end{array}$

$\begin{array}{lll}43 & \mathbf{6 6} & 47\end{array}$

$\begin{array}{lll}77 & 38 & 45\end{array}$

$\begin{array}{lll}20 & 44 & 37\end{array}$

$\begin{array}{lll}17 & 90 & 39\end{array}$

$\begin{array}{lll}26 & 80 & 40\end{array}$

$\begin{array}{lll}17 & 92 & 40\end{array}$

$\begin{array}{lll}17 & 92 & 39 \\ 20 & 95 & 38\end{array}$

$\begin{array}{lll}17 & 32 & 37\end{array}$

$\begin{array}{lll}29 & 25 & 35\end{array}$

$\begin{array}{lll}16 & 35 & 32\end{array}$

$\begin{array}{lll}16 & 35 & 32 \\ 30 & 28 & 31\end{array}$

$\begin{array}{lll}22 & 22 & 25\end{array}$

$\begin{array}{lll}8 & 43 & 18\end{array}$

$\begin{array}{lll}8 & \mathbf{4 3} & 18 \\ 9 & \mathbf{4 2} & 18\end{array}$

$\begin{array}{llll}7 & 9 & \mathbf{4 2} & 18 \\ 6 & 9 & 20 & 17\end{array}$

$\begin{array}{llll}4 & 7 & \mathbf{1 8} & 17 \\ 6 & & 8 & 10\end{array}$

$\begin{array}{llll}6 & 7 & 8 & 9\end{array}$

\begin{tabular}{cccc}
9 & 9 & 10 & 10 \\
\hline 26 & 30 & 48 & 37 \\
\hline
\end{tabular}


Note. For each PLE listed the purpose of use with the greatest frequency is given in boldface.

In Table 3, frequencies regarding the students' 24 most widely used PLEs are provided. Accordingly, Gmail is the most commonly used environment $(n=69)$. This was respectively followed by Facebook $(n=64)$, Google Drive $(n=59)$, YouTube $(n=58)$, Google Search $(n=54)$, and Wikipedia $(n=52)$. On the other hand, the least reported environment was iGoogle $(n=9)$. It was followed in ascending order of frequency by Google Calendar $(n=10)$, Flicker $(n=10)$, Vimeo $(n=17)$, and Myspace $(n=$ 18). The environments not included in the scale that students wanted to add were LinkedIn $(n=5)$, Snapchat $(n=3)$, WhatsApp ( $n=5)$, Hangout $(n=4)$, Instagram $(n=2)$, Pinterest $(n=1)$, Evernote ( $n$ $=1)$, and Tumblr $(n=2)$. These environments can be considered and added to the scale in future studies.

Looking at the general context of the learning process, PLEs are most commonly used in sharing processes $(n=48)$. They are thereafter respectively used most in access $(n=43)$ and manage $(n=30)$ processes. The number of students using PLEs in the construct process was smaller compared to other processes $(n=26)$. In access processes the most commonly used PLEs were, respectively, Wikipedia $(n=102)$, YouTube $(n=99)$, and Google Search $(n=98)$. In the construct process, Google Drive $(n=$ $58)$, Gmail $(n=51)$, and Facebook $(n=59)$ were used. The most widely used PLEs by students in management processes were Gmail $(n=88)$, Google Drive $(n=85)$, and Dropbox $(n=77)$, while they preferred PLEs such as Facebook ( $n=97)$, MSN Messenger $(n=95)$, and Skype $(n=92)$ in sharing processes.

Table 3 imply that although every PLE is used for a more common purpose it is also used for the other purposes. For example, Wikipedia is more commonly used to access $(\mathrm{n}=102)$ learning content (such as by getting texts, pictures, graphics, tables, formulas etc.) it is also used to construct learning (such as by writing in one or creating one), manage learning (such as by adding, saving, archiving or deleting a bit of one) and share learning (such as sharing with a community of learning and/or community of interest). When counting the bold numbers in the table, which are showing the most common use of a specific PLE, it is seen that 10 of the all 24 PLEs is most commonly used to access $(n=11)$ and share $(n=9)$ while only one of them (Google Docs) is most commonly used to construct and 3 of them (Gmail, Google Drive, and Dropbox) are used to manage learning. This result imply a need for more PLEs that companies create for the processes of construct and manage learning or a need for shifting teacher education programs to more active and constructive curricula. This indicate the need for further investigations that include more PLEs and cross comparisons among different teacher education programs.

Table 4 demonstrate correlations between perceptions of PLEs and uses of PLEs. The only significant correlation is between perception of usability of PLEs and use PLEs for share $(r=.20 ; p<.05)$.

Table 4

Correlation among Perceptions of PLEs and use of PLEs $(N=109)$

\begin{tabular}{lccccc}
\hline & \multicolumn{4}{c}{ Use of PLEs } \\
\cline { 3 - 5 } PLE & Access & Construct & Manage & Share \\
\hline Perception of Usability & Pearson $r$ & .06 & .07 & .02 & .20
\end{tabular}




\begin{tabular}{llllll} 
& $\mathrm{p}$ & .50 & .50 & .87 & .04 \\
\hline Perception of Usefulness & Pearson $\mathrm{r}$ & .08 & .07 & .09 & .15 \\
& $\mathrm{p}$ & .40 & .49 & .34 & .13 \\
\hline Perception of Limitations & Pearson $\mathrm{r}$ & .03 & .02 & .01 & .16 \\
& $\mathrm{p}$ & .77 & .87 & .90 & .09 \\
\hline
\end{tabular}

Note: $p<.05$

There was no significant difference between the genders in terms of the perceptions and usage levels of PLEs in intergroup comparisons on the whole (Table 5). While studies of computer technologies tend to produce results showing that female students have lower acceptance rates and usage levels of such tools (Kadijevich, 2000; Liaw, 2002; Broos, 2005), the lack of a difference in the present study might be because the technologies explored here were social technologies in principle (Kadijevich, 2000; Liaw, 2002; Broos, 2005). Survey results showing that women are more effective in social environments support this argument (Tüfekci, 2008; Mazman \& Usluel, 2011; Pew Research Center, 2014). Furthermore, technology designers have worked to eliminate digital inequality by reflecting gender-related differences in their designs in recent years.

Table 5

Summary Results of Independent Sample T-Test for Gender Comparisons $\left(n_{\text {Girls }}=66, n_{\text {Boys }}=43\right)$

\begin{tabular}{llcccc}
\hline & Gender & $\boldsymbol{M}$ & $\boldsymbol{S D}$ & $\boldsymbol{t}$ & $\boldsymbol{p}$ \\
\hline Perception of Usability & Female & 4.35 & .50 & 1.12 & .26 \\
& Male & 4.24 & .51 & & \\
\hline Perception of Usefulness & Female & 4.00 & .50 & .50 & .62 \\
& Male & 3.95 & .58 & & \\
\hline Perception of Limitations & Female & 3.07 & .81 & -.32 & .75 \\
& Male & 3.12 & .86 & & \\
\hline Use for Access & Female & 9.20 & .38 & -.93 & .36 \\
& Male & 10.00 & .48 & & \\
\hline Use for Construct & Female & 5.55 & .03 & -.52 & .61 \\
& Male & 5.98 & .59 & & \\
\hline Use for Manage & Female & 6.26 & .66 & -.96 & .34 \\
& Male & 7.00 & .39 & & \\
\hline Use for Share & Female & 10.32 & .24 & -.53 & .60 \\
& Male & 10.77 & .45 & & \\
\hline
\end{tabular}


When we look at the impact of program year on the results (Table 6) we identify a significant difference between $2^{\text {nd }}$ and $4^{\text {th }}$ year students on the perception of usefulness $(F=6.575 ; p<.01)$ and another significant difference between $2^{\text {nd }}$ and $4^{\text {th }}$ year students about the use for share $(F=4.424 ; p$ $<.05)$. Given that students, who are of the y generation, are naturally inclined toward the use of technology and have positive perceptions from the very beginning, whereby technology usage in education is something to be expected (Waterworth, 2013). It can be assumed that this is the cause of a lack of significant difference among program year in terms of other results. However, year of study could be expected to make a difference in the case of similar research repeated for different educational programs.

Table 6

Summary Results of ANAOVA Test for Program Year Comparisons $\left(n_{2}=23, n_{3}=41, n_{4}=45\right)$

\begin{tabular}{|c|c|c|c|c|c|c|c|c|c|}
\hline & Grade & $M$ & SD & & SS & $\underline{d f}$ & MS & $\boldsymbol{F}$ & $\mathbf{p}$ \\
\hline \multirow{3}{*}{$\begin{array}{l}\text { Perception of } \\
\text { Usability }\end{array}$} & 2 & 4.24 & 0,55 & Between Groups & .423 & 2 & .211 & .842 & .434 \\
\hline & 3 & $4 \cdot 38$ & 0,53 & Within Groups & 26.622 & 106 & .251 & & \\
\hline & 4 & 4.27 & 0,45 & Total & 27.045 & 108 & & & \\
\hline \multirow{3}{*}{$\begin{array}{l}\text { Perception of } \\
\text { Usefulness }\end{array}$} & 2 & 3.89 & 0,54 & Between Groups & .313 & 2 & .157 & .555 & .576 \\
\hline & 3 & 3.97 & 0,49 & Within Groups & 29.953 & 106 & .283 & & \\
\hline & 4 & 4.03 & 0,56 & Total & 30.266 & 108 & & & \\
\hline \multirow{3}{*}{$\begin{array}{l}\text { Perception of } \\
\text { Limitations }\end{array}$} & 2 & 3.56 & 0,83 & Between Groups & 8.133 & 2 & 4.067 & 6.575 & .002 \\
\hline & 3 & 2.82 & 0,78 & Within Groups & $65 \cdot 557$ & 106 & .618 & & \\
\hline & 4 & 3.10 & 0,77 & Total & 73.69 & 108 & & & \\
\hline \multirow{3}{*}{ Use for Access } & 2 & 9.83 & 4,03 & Between Groups & $55 \cdot 591$ & 2 & 27.796 & 1.437 & .242 \\
\hline & 3 & 8.61 & 4,38 & Within Groups & 2049.638 & 106 & 19.336 & & \\
\hline & 4 & 10.18 & 4,58 & Total & 2105.229 & 108 & & & \\
\hline \multirow{3}{*}{ Use for Construct } & 2 & 6.57 & 5,14 & Between Groups & 60.307 & 2 & 30.153 & 1.695 & .189 \\
\hline & 3 & 4.78 & 3,86 & Within Groups & 1885.877 & 106 & 17.791 & & \\
\hline & 4 & 6.13 & 4,01 & Total & 1946.183 & 108 & & & \\
\hline \multirow{3}{*}{ Use for Manage } & 2 & 6.96 & 5,00 & Between Groups & 83.607 & 2 & 41.804 & 2.75 & .068 \\
\hline & 3 & 5.44 & 3,02 & Within Groups & 1611.365 & 106 & 15.202 & & \\
\hline & 4 & $7 \cdot 36$ & 3,98 & Total & 1694.972 & 108 & & & \\
\hline \multirow{3}{*}{ Use for Share } & 2 & 9.91 & 4,68 & Between Groups & 154.489 & 2 & 77.245 & 4.424 & .014 \\
\hline & 3 & 9.29 & 4,10 & Within Groups & 1850.758 & 106 & 17.46 & & \\
\hline & 4 & 11.89 & 3,98 & Total & 2005.248 & 108 & & & \\
\hline
\end{tabular}

Note. ${ }^{*}$ Tukey test was used for posthoc comparisons. Significant values are given in boldface.

\section{Conclusion}


The results reveal the validity and reliability of the structure of the PLE Perception Scale, consisting of 3 principal components (usability, usefulness, and limitations) and 11 items. The data acquired from the scale demonstrate that students find it easy to use PLEs. Students can easily access learning contents and interact with other users within these environments. By allowing for personal preference and control, PLEs also ensure ease of usage. Whereas students find these environments useful in personal development, socialization, and learning, they have positive perceptions regarding the shared contents' validity, as well.

All of the students use PLEs in their learning processes. However, this usage is focused more on access and sharing purposes than on purposes of management or construction in learning. The PLEs attracting the most users are email, social networks, document sharing, video sharing, search engines, and encyclopedias.

Along with their many positive features, the negative aspects of PLEs also come into question. The Q\&A cycles that emerge during usage can make the use of PLEs boring. Moreover, a significant proportion of the students surveyed believe that they are exposed to phishing in these virtual environments. On the other hand, the students generally do not have a negative perception about cyberbullying, which is a major problem in virtual environments (Park, Na, Kim, 2014; Beckman, Hagquist, \& Hellström, 2013; Adams, 2010).

PLEs make students more active in their own learning processes (Marin et al., 2014). However, the low rate of application of PLEs to construction and management in learning as compared to the usage for access and sharing can be considered inadequate for obtaining active learning outcomes. Active learning means learners engage with the learning content and construct it by collaborating with the other learners (Kane, 2001; Adams \& Burns, 1999; Meyers \& Jones, 1993). Students learn more when they participate in the process of learning, whether it's through discussion, practice, review, or application (Grunert, 1997). To consider this situation simply as a personal learning preference or habit of the participants would not be a sufficient explanation. It may indicate that teacher education curricula are not adequate on the basis of personal learning. In light of this, the question of how teacher education programs encourage personal learning skills can be suggested as a new avenue of research. In addition, the PLE usage among different educational programs can be addressed comparatively, and the relationship between personal learning skills can be examined.

Similar descriptive studies that would contribute to the ongoing design of these environments are expected to be especially important in the future (Johnson \& Sherlock, 2014). Intercultural comparisons would also be helpful in order to see the effect of cultural influences on the usage of PLEs. In addition, studies that aim to reach a wider audience would help to increase the generalizability of the results. Conducting qualitative studies to reveal how findings derived from numerical data change according to the particular scale that is used and the details regarding personal use would also be helpful.

This study has a couple of limitations in that it was executed only with 109 preservice student teachers and no cross-validation was done. Therefore, we recommend readers be careful when generalizing the survey instruments and the results. We also recommended that future researchers include an examination of perception changes based on types of PLEs or the central purpose or affordance of different PLEs. 


\section{References}

Adams, C. (2010). Cyberbullying: How to make it stop, Instructor, 12O(2), 44-49.

Adams, S., \& Burns, M. (1999). Connecting student learning and technology. Washington, DC: Office of Educational Research and Improvement. Retrieved from http://www.bazzirk.com/sedl/files/images/pub cslt.pdf

Attwell, G. (2007). E-Portfolios: The DNA of the personal learning environment? Journal of Elearning and Knowledge Society, 3(2), 39-61.

Beckman, L., Hagquist, C., \& Hellström, L. (2013). Discrepant gender patterns for cyberbullying and traditional bullying: An analysis of Swedish adolescent data. Computers in Human Behavior, 29, 1896-1903.

Broos, A. (2005). Gender and information and communication technologies (IT) anxiety: Male self assurance and female hesitation. CyberPsychology \& Behaviour, 8(1), 21-31.

Buchem, I. (2012). Psychological ownership and personal learning environments: Do possession and control really matter? In Proceedings of the PLE Conference 2012. Retrieved from http://revistas.ua.pt/index.php/ple/article/viewFile/1437/1323

Buchem, I., Attwell, G., \& Torres, R. (2011). Understanding personal learning environments: Literature review and synthesis through the activity theory lens. In Proceedings of the The PLE Conference 2011. Retrieved from http://journal.webscience.org/658

Byrne, B. M. (2009). Structural equation modeling with AMOS: Basic concepts, applications, and programming (2nd ed.). New York: Taylor \& Francis Group.

Chan, T., Corlett, D., Sharples, M., Ting, J., \& Westmancott, O. (2005). Developing interactive logbook: A personal learning environment. IEEE International Workshop on Wireless and Mobile Technologies in Education, Proceedings (pp. 73-75). doi: 10.1109/Wmte.2005.16

Chatti, M. A., Dakova, S., Thüs, H., \& Schroeder, U. (2013). Tag-based collaborative filtering recommendation in personal learning environments. IEEE Transactions in Learning Technologies, 6(4), 337-349.

Chatti, M. A., Jarke, M., \& Specht, M. (2010). The 3P learning model. Educational Technology \& Society, 13(4), 74-85.

Childnet International. (2013). Cyberbullying supporting school staff. Retrieved from http://www.digizen.org/downloads/cyberbullying teachers.pdf

Cohen, L., Manion, L., \& Morrison, K. (2003). Research methods in education (6th ed.). London, UK: Routledge Falmer.

Comrey, A. L., \& Lee, H. B. (1992). A first course in factor analysis (2nd ed.). Hillsdale, NJ: Lawrence Erlbaum Associates. 
Conde, M., García-Peñalvo, F. J., Alier, M., \& Piguillem, J. (2013). The implementation, deployment and evaluation of a mobile personal learning environment. Journal of Universal Computer Science, 19(7), 854-872.

Cseh, M., \& Manikoth, N. N. (2011). Invited reaction: Influences of formal learning, personal learning orientation, and supportive learning environment on informal learning. Human Resource Development Quarterly, 22(3). doi: 10.1002/hrdq.20084

Dabbagh, N., \& Kitsantas, A. (2012). Personal Learning Environments, social media, and selfregulated learning: A natural formula for connecting formal and informal learning. Internet and Higher Education, 15, 3-8.

Davis, F. D. (1989). Perceived usefulness, perceived ease of use, and user acceptance of information technology. MIS Quarterly, 13(3), 319-340.

Downes, S. (2006). Learning networks and connective knowledge: Discussion paper \#92 [online document]. Retrieved from http://it.coe.uga.edu/itforum/paperg2/paperg2.html

Drexler, W. (2010). The networked student model for construction of personal learning environments: Balancing teacher control and student autonomy. Australasian Journal of Educational Technology, 26(3), 369-385.

Educause Learning Initiative (2009). Things you should know about personal learning environments. Retrieved from http://net.educause.edu/ir/library/pdf/ELI7049.pdf

Fiedler, S. H. D., \& Väljataga, T. (2011), Personal learning environments: concept or technology? International Journal of Virtual and Personal Learning Environments, 2(4), 1-11.

Fiedler, S. H. D., \& Väljataga, T. (2011). Personal learning environments: Concept or technology? International Journal of Virtual and Personal Learning Environments, 2(4), 1-11.

Fiedler, S. H. D., \& Väljataga, T. (2013). Personal learning environments: A conceptual landscape revisited. eLearning Papers, 35, 1-16.

Fournier, H., \& Kop, R. (2012). Researching the design and development of a Personal Learning Environment. NRC Publications Archive (NPArC). Retrieved from http://nparc.cisti-icist.nrccnrc.gc.ca/npsi/ctrl?action $=$ rtdoc\&an $=16285584$ \&lang $=$ en

Fourier, H., Kop, R., \& Hanan, S. (2012). The value of learning analytics to networked learning on a Personal Learning Environment. NRC Publications Archive. Retrieved from http://nparc.cisti-icist.nrc-cnrc.gc.ca/npsi/ctrl?action=rtdoc\&an=18150452\&lang=en

Fournier, H., Kop, R., \& Durand, G. (2014). Challenges to Research in MOOCs. MERLOT Journal of Online Learning and Teaching, 10(1), 1-15.

Godwin-Jones, R. (2009). Emerging technologies Personal Learning Environments. Language Learning \& Technology, 13(2), 3-9. 
Grunert, J. 1997. The course syllabus: A learning-centered approach. Bolton, MA: Anker.

Hicks, A., \& Sinkinson, C. (2015). Critical connections: Personal learning environments and information literacy. Research in Learning Technology, 23, 1-12.

Hinton, P.R. (2004). Statistics explained, (2nd ed.). London: Routledge.

Jeremic, Z., Jovanovic, J., \& Gasevic, D. (2011). Personal learning environments on the social semantic web. Retrieved from http://dl.acm.org/citation.cfm?id=2595057

Johnson, M., Hollins, P., Wilson, S., \& Liber, O. (2006). Towards a reference model for the personal learning environment: Who's Learning? Whose Technology? In Proceedings of the $23^{\text {rd }}$ annual ascilite conference: Who's learning? Whose technology? Australia.

Johnson, M., \& Liber, O. (2008) The Personal Learning Environment and the human condition: From theory to teaching practice. Interactive Learning Environments, 16(1), 3-15. doi: 10.1080/10494820701772652

Johnson, M. W., \& Sherlock, D. (2014). Beyond the Personal Learning Environment: Attachment and control in the classroom of the future. Interactive Learning Environments, 22(2), 146-164.

Juarros, V. M., Ibáñez, J. S., \& Crosetti, B. B. (2014). Research results of two personal learning environments experiments in a higher education institution. Interactive Learning Environments, 22(2), 205-220. doi: 10.1080/10494820.2013.788031

Kadijevich, D. (2000). Gender differences in computer attitude among ninth-grade students. Journal of Research on Computing in Education, 22(2), 145-154.

Kane, L. (2001). Educators, learners and active learning methodologies. International Journal of Lifelong Education, 23(3). 275-286.

Kazançoğlu, İ., Üstündağlı, E., \& Baybars, M. (2010). Facebook kullanıcılarının Facebook’ta yayınlanan reklam türlerine yönelik tutum analizi. Ulusal Pazarlama Kongresi, 15, (pp. 160163).

Liaw, S. S. (2002). An Internet survey for perceptions of computers and the World Wide Web: relationship, prediction, and difference. Computers in Human Behavior, 18(1), 17-35.

Liber, O., \& Johnson, M. (2008) Personal Learning Environments. Interactive Learning

Environments, 16(1), 1-2. doi: 10.1080/10494820701772645

Marin, V., Negre, F., \& Perez, A. (2014). Construction of the foundations of the PLE and PLN for collaborative learning. Comunicar, 21(42), 35-43. doi: 10.3916/C42-2014-03.

Mazman, G., \& Usluel, Y. K. (2011) Gender differences in social networks. The Turkish Online Journal of Educational Technology, 10(2), 133-139. 
McLoughlin C., \& Lee, J. W. (2010). Web 2.o-based e-learning: Applying social informatics for tertiary teaching, New York: Information Science Reference.

Meyers, C \& Jones, B. T. (1993). Promoting active learning (1st ed.). San Francisco: Jossey-Bass.

Milligan, C. D., Beauvoir, P., Johnson, M. W., Sharples, P., Wilson, S., \& Liber, O. (2006). Developing a reference model to describe the personal learning environment. Innovative Approaches for Learning and Knowledge Sharing, Lecture Notes in Computer Science, 4227, 506-511.

Mitsuhara, H., \& Kurose, Y. (1999). Individual teaching material system in personal learning environment using internet. Advanced Research in Computers and Communications in Education, 1, 55, 1076-1079.

Mödritscher, F. (2010). Towards a Recommender Strategy for Personal Learning Environments. In Proceedings of the 1st Workshop on Recommender Systems for Technology Enhanced Learning (RecSysTEL 2010) (2775-2782). doi:10.1016/j.procs.2010.08.002

Notar, C. E., Padgett, S., \& Roden, J. (2013). Cyberbullying: A review of the literature. Universal Journal of Educational Research 1(1), 1-9.

Oliveira, L., \& Moreira, F. (2010). Personal Learning Environments: Integration of Web 2.0 Applications and Content Management Systems. In Proceedings of the 11th European Conference on Knowledge Management (pp. 1171-1177). Academic Publishing Limited.

O'Reilly, T. (2006, December 10). Web 2.0 compact definition. Radar. Retrieved from http://radar.oreilly.com/

Park, S., Na, E. Y., \& Kim, E. (2014). The relationship between online activities, netiquette and cyberbullying. Children and Youth Services Review, 42, 74-81. Retrieved from http://dx.doi.org/10.1016/j.childyouth.2014.04.002

Park, S. Y. (2009). An analysis of the technology acceptance model in understanding university students' behavioral intention to use e-Learning. Educational Technology \& Society, 12(3), 150-162.

Powell, S., Tindal, I. \& Millwood, R. (2008) Personalized learning and the Ultraversity experience. Interactive Learning Environments, 16(1), 63-81. doi:10.1080/10494820701772710

Pew Research Center (2014). Social networking fact sheet. Retrieved from http://www.pewinternet.org/fact-sheets/social-networking-fact-sheet/

Saadatmand, M., \& Kumpulainen, K. (2012). Content aggregation and knowledge sharing in a personal learning environment: Serendipitous and emergent learning in open online networks. In 2012 15th International Conference on Interactive Collaborative Learning (ICL) (pp. 1-8). doi: 10.1109/ICL.2012.6402224 
Salehi, M., Kamalabadi, I. N., \& Ghoushchi, M. B. G. (2013). An effective recommendation framework for Personal Learning Environments using a learner preference tree and a GA. IEEE Transactions on Learning Technologies, 6(4), 350-363. doi: 10.1109/Tlt.2013.28

Severance, C., Hardin, J., \& Whyte, A. (2008). The coming functionality mash-up in personal learning environments. Interactive Learning Environments, 16(1), 47-62. doi: 10.1080/10494820701772694

Shaikh, Z. A., \& Khoja, S. A. (2014). Personal learning environments and university teacher roles explored using Delphi. Australasian Journal of Educational Technology, 3o(2).

Shankar, A., Elliott, R., \& Fitchett, J. (2009) Consumption, identity and narratives of socialization. Marketing Theory, 9(1):75-94. doi: 10.1177/1470593108100062

Shroff, R. H., Deneen, C. C., \& Eugenia, M. W. (2011). Analysis of the technology acceptance model in examining students' behavioral intention to use an eportfolio system. Australasian Journal of Educational Technology, 27(4), 600-618.

Stevens, J. P. (2009). Applied multivariate statistics for the social sciences (5 $5^{\text {th }}$ ed.). New York, NY: Routledge.

Tabachnick, B. G., \& Fidell, L. S. (2013). Using Multivariate Statistics (6 $6^{\text {th }}$ ed.). Boston, MA: Pearson.

Teo, T. (2009). Evaluating the intention to use technology among student teachers: A structural equation modeling approach. International Journal of Technology in Teaching and Learning, 5(2), 106-118.

Teo, T. (2010). Examining the influence of subjective norm and facilitating conditions on the intention to use technology among pre-service teachers: A structural equation modeling of an extended technology acceptance model. The Asia-Pacific Education Researcher, 11(2), 253-262.

Tüfekci, Z. (2008). Gender, social capital and social network(ing) sites: Women bonding, men searching. Paper presented at the American Sociological Association Annual Meeting, Boston, MA. Retrieved from http://www.allacademic.com/meta/p242696 index.html

Ursavaş, Ö. F., Şahin, S., \& Mcilroy, D. (2014). The role of discipline in determining Turkish preservice teachers' behavioral intentions to use ICT. Education and Science, 39(175), 136-153.

Valjataga, T., \& Laanpere, M. (2010). Learner control and personal learning environment: A challenge for instructional design. Interactive Learning Environments, 18(3), 277-291. doi: $10.1080 / 10494820.2010 .500546$

Valtonen, T., Hacklin, S., Dillon, P., Vesisenaho, M., Kukkonen, J., \& Hietanen, A. (2012). Perspectives on personal learning environments held by vocational students. Computers \& Education, 58, 732-739.

Waterworth, N. (2013, April 9). Generation X, generation Y, generation Z, and the baby boomers. Retrieved from http://www.talentedheads.com/ 
White S., \& Davis H. (2011). Making it rich and personal: crafting an institutional personal learning environment. International Journal of Virtual and Personal Learning Environments, 2(3), 118.

Wilson, S. (2008). Patterns of personal learning environments. Interactive Learning Environments, 16(1), 17-34. doi: 10.1080/10494820701772660

\section{Athabasca}

University

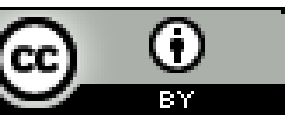

